Marquette University

e-Publications@Marquette

$1-1-1995$

\title{
Is Emotive Theory the Philosopher's Stone of the Ordinalist Revolution?
}

John B. Davis

Marquette University, john.davis@marquette.edu

Published version. "Is Emotive Theory the Philosopher's Stone of the Ordinalist Revolution?" in Measurement, Quantification and Economic Analysis. Ed. Ingrid Hahne Rima. London: Taylor \& Francis (Routledge), 1995: 318-332. Publisher Link. (C) 1995 Taylor \& Francis (Routledge). Used with permission. 


\title{
Is emotive theory the philosopher's stone of the ordinalist revolution?
}

\author{
John B. Davis
}

In the latter half of the twentieth century economics has come to be regarded as a science little different in its use of scientific methods from the longer established natural sciences. In good part this has been due to economists' adoption of sophisticated mathematical models and state-of-the-art econometric techniques that permit empirical testing of formally expressed causal relationships. Science since Newton has been understood to be mathematical in nature, and good science has for an even longer time depended upon evaluating theory according to its ability to explain and predict observable events. But is economic behavior truly governed by causal laws? The foundation of modern economics is the theory of individual choice, and while we say that circumstances often occasion the choices individuals make, it seems inappropriate to make the stronger claim that choices are actually caused. Given this, it seems odd that economic behavior is modeled in terms of relationships between independent and dependent variables, where the former cause or bring about the latter. Indeed one might go so far as to say that the reliance on mathematical functions to represent human behavior is a misuse of mathematics, and that economics should return to an earlier practice of producing more descriptive, qualitative analysis. ${ }^{1}$

The argument in this chapter is somewhat more modest. Here it is argued that there are significant limitations on the use of mathematics in economics on account of the nature of choice behavior, and that these limits have been generally overstepped by economists anxious to legitimate social science thinking in the wider scientific community. The immediate thesis of the chapter is that an important problem in contemporary economics is its systematic misapprehension of the nature of practical reasoning or practical inference. This misapprehension, it is argued, principally derives from the widespread acceptance of Lionel Robbins's critique of value judgments and ethics advanced more than a half century ago in his influential methodological tract An Essay on the Nature and Significance of Economic Science (1932, 1935). Value judgments and ethical argument of course are only one species of practical reasoning. Indeed, pragmatic reasoning without ethical implication is an equally if not more pervasive form of practical inference. However, 
Robbin's treatment of value judgments and ethics, which we will see in key respects followed the logical positivists' emotivist critique of ethics of the 1920s and 1930s, applies equally to other forms of practical reasoning. Thus Robbins was in effect responsible for a more general critique of practical reasoning and inference which, it will be argued here, subsequently encouraged a mistaken understanding of economic behavior among later economists. In essence, Robbins's Essay convinced most economists that economics was properly thought a natural science in its scientific methodology, when a reasonable assessment of the nature of practical reasoning in which economic agents engage should have produced the view that economics possessed distinctive characteristics as a social science.

The chapter develops these conclusions in several stages. In the next section, the principal differences between deductive or demonstrative reasoning and practical reasoning are set forth with special attention to the significance of these differences for understanding economics as a social science. In the third section, Robbins's characterization of value judgments and the connection between his arguments and those of the logical positivists A. J. Ayer and C. L. Stevenson are examined. The principal implication of Robbins's critique, it will be seen, is the idea that economics is a natural science that focuses on truth and causality. In the fourth section, we look at the importance of choice behavior in economics and the reasons for saying that economics cannot be treated as a natural science but must rather be understood as a social science. Finally in the concluding section, the topics of measurement, quantification and the empirical work in economics are briefly discussed with the aim of outlining the limits of quantitative methods in economics.

\section{FORMS OF REASONING}

Economists do not always appreciate that the choice behavior they study falls within a broader domain of practical reasoning whose logic has been long investigated by philosophers, logicians and, more recently, decision theorists. Yet it is important to see choice behavior as being part of this larger framework, since this serves to distinguish it as a specific form of reasoning with its own particular requirements. Perhaps the easiest way to see what this involves is to allude briefly to Aristotle who, in a basic distinction since maintained by philosophers and logicians, distinguished reasoning by its subject matter as either scientific or practical. Scientific or demonstrative reasoning, first of all -i.e. what is now characterized as deductive reasoning in formal logic-concerns the relation of entailment, whereby valid inferences from true premises entail true conclusions. The relation of entailment, it should be emphasized, is a relation of necessity, such that should one profess belief in the truth of the premises of a valid syllogism, then one can fairly be accused of inconsistency should one deny the truth of its conclusion. Thus, 
for Aristotle, demonstrative reasoning was scientific in that the natural world, which he took to be the sole domain of science, was constituted of invariable relationships or laws whose investigation demonstrative reasoning assisted. On this view, given some generalization from experience that all x's are A's, should we find some entity we know to be an $\mathrm{x}$, we would then be entitled to infer with certainty that this $\mathrm{x}$ was also an $\mathrm{A}$.

The importance of demonstrative or deductive reasoning to the expansion and development of natural science can hardly be exaggerated. Its model of science is of a nomological and verificationist form of investigation, the object of which is to elaborate highly confirmed generalizations, sometimes referred to as laws of nature, which may function as major premises of theoretical syllogisms. Indeed, attendant to this logical conception there has also developed a philosophy of the meaning of general relationships, namely, that they reflect causal connections or causal laws that operate in the world itself. That $a$ is always followed by $b$ tells us that $b$ is necessary for $a$ and thus a cause of a. Natural scientists have thus made one of their chief preoccupations the empirical substantiation of general relationships. While the empirical testing of such relationships is a complicated matter - something made increasingly evident in debates in recent decades in the philosophy of science - in the main, natural scientists still take as their principal task the explanation of causal connections in the world through the use of demonstrative reasoning and empirical analysis.

In contrast, practical reasoning or inference, though it may also be represented in syllogistic form, is fundamentally different from demonstrative reasoning on account of the fact that its conclusion is something that one ought to do (in either moral or pure pragmatic terms), not something said to be true. That is, practical reasoning prescribes, and is reasoning leading toward action, whereas demonstrative reasoning describes, and is reasoning toward the truth of a conclusion. This difference is significant with respect to our different relations to the respective conclusions of theoretical and practical syllogisms. As noted, in demonstrative reasoning one cannot consistently deny the truth of a conclusion validly inferred from true premises. One is compelled to accept the truth of such a conclusion on pain of being inconsistent. With practical syllogisms, however, the conclusion of an argument, say, that one ought to perform some action does not in itself compel one to perform that action. Suppose, for example, that some practical argument produces the conclusion that a certain action is desirable. We all recognize that an individual may accept such an argument yet still fail to desire the action called for. Nor, moreover, are we inclined to say that this involves some sort of inconsistency. Thus, whereas demonstrative reasoning concerns relationships which are necessitous and invariable, practical reasoning concerns relationships which are contingent and variable.

This distinction has functioned in one form or another throughout much of the history of modern science, with causal relationships being central to 
natural science reasoning, and social science making individuals' practical reasoning behavior central to the examination of society. Indeed social scientists have often emphasized that their fields differ from the natural sciences by their assumption that social agents engage in purposive behavior and intentional action, so that the explanation of human conduct - both of individuals and groups of individuals - requires analysis of the processes of practical inference this presupposes. ${ }^{2}$ As might be expected, however, this creates significant difficulties for causal analysis in social science. While a few have argued that mental events are a part of nature and can both cause and be caused in a law-like manner (Davidson 1980), most seem to agree that when one is asked why an intentional act was performed, the answer is not to be defined in terms of natural or psychological processes but in terms of a request for reasons (Anscombe 1957). In essence, intentions are characteristically cognitive phenomena, and as such cannot be understood in terms of patterns of cause and effect, which have very little if anything to tell us about the psychological world of motives, reasons and intentions.

Certainly, then, much more might be said on the subject of the character of practical reasoning. What needs to be emphasized here, however, is that the practice of employing natural science methods in economics - whereby economic choices are modeled as cause and effect relationships - implicitly makes specific assumptions about what must pass as practical reasoning in the realm of economic behavior. In the natural science model, the economist's principal task is to establish law-like generalizations about economic behavior that predict future behavior on the basis of past experience. This assumes, however, that economic agents are governed by causal relationships rather than engage in a practical reasoning that may redirect the future away from the pattern of past events. Suppose it is thought that the proposition that all $x$ 's are A's constitutes a law-like generalization in economic life. Then an economic agent who encounters an entity said to be truly an $\mathrm{x}$ must act in accordance with the proposition that all x's are A's. Since economic behavior is thought to involve reasoning capacity, an individual's failure to observe laws that pertain to economic life might indeed be considered a failure of rationality. In the language used above, a reasoning agent able to recognize true propositions and understand valid inference is thus compelled to act as demonstrative reasoning and economic laws dictate.

We will return to this argument below. Here it only needs to be noted that the obviously unacceptable implication of this interpretation of economic choice is that it makes economic behavior deterministic. On the natural science model of explanation, we seek law-like generalizations, because they are believed to reflect underlying causal relationships. Yet it is the consensus among philosophers, most social scientists and everyday individuals that human behavior is inadequately explained on this model. Though it may be possible to inject causal thinking into our accounts of human behavior, this is only done by ignoring the vast tide of intentional phenomena that appear 
to obey and be ruled by an altogether different logic. Aristotle sought to capture this distinct component of human behavior by the notion that practical reasoning does not compel its conclusions as does theoretical reasoning. Modern thinking understands practical reasoning as purposive behavior and intentional action. Agents' actions are informed by their intentions in that they act in accordance with their intentions, while their intentions themselves are formed according to their goals and ends. These goals and ends are then themselves evaluated and redetermined as we observe how well our actions fit our intentions.

Given all this, the assertion that most economists employ the methods of natural science as their model for explaining economic behavior might well seem paradoxical. The theory of price determination that constitutes the main body of current economic theory stems from an analysis of what economists term agent choice behavior. Central to the idea of choice, however, is the assumption that individuals are not compelled to act in certain ways. Thus how could it have been thought by Robbins that economics was best thought to be - as he explicitly insisted - a natural science? This puzzle is important for more than historical reasons. At issue is the contemporary understanding of economic method and the conception of economics as a science. To better approach these larger issues, we turn to Robbin's own thinking and the influences upon it during his time from the logical positivists.

\section{ROBBINS AND THE EMOTIVISTS}

To understand Robbins's critique of ethics and value judgments in his Essay, it is valuable to have some basic acquaintance with arguments that the logical positivists advanced regarding ethical statements in the same decade as the Essay was written. The logical positivists were a group of philosophers and scientists that formed in Vienna in the 1920s and 1930s to argue for a rigorously empiricist approach to science. ${ }^{3}$ Though Robbins did not make special reference to the views of the logical positivists in his own works, the assumption here is that his thinking was indirectly influenced by their arguments, because their ideas had wide appeal, were widely discussed at the time and offered the promise of scientific respectability which Robbins valued. Irrespective of the question of influence, however, Robbins's own views bear striking resemblance to many of those adopted by the logical positivists. First and foremost was a common commitment to the project of demarcating science from non-science. For both Robbins and the logical positivists, science by the 1930s still suffered from undesirable admixtures of ethics and metaphysics. Second, there was a conviction on behalf of both that non-scientific ideas could be purged from science by the conscious adoption of the psychological causes and effects that tended to be associated with their utterance. "The emotive meaning of a word is the tendency of a word, arising through the history of its usage, to produce (result from) affective responses 
in people" (Stevenson 1937: 14). As a theory of ethical language, emotivism was thus an early form of what ethics philosophers now characterize as noncognitivism. Ethical language is non-cognitive on this view, because it is an incidental, in itself meaningless, accompaniment to an underlying causal process involved in individuals' efforts to pursue their interests through psychological manipulation. This underlying causal process could be explained in standard natural science terms using deductive logic and empirical analysis, but ethical language in itself is meaningless. Thus, whereas scientific statements possessed descriptive meaning in virtue of their (empirically verifiable) representation of the causal connections we find in the world, ethical statements had what Stevenson distinguished as causal meaning in that we use this kind of language purely because psychological circumstances stimulate us to do so. ${ }^{4}$

Given this, it is not difficult to see that the emotivist doctrine provided valuable support for the logical positivists' main contention that science could be demarcated from non-science. It was commonplace that people argued a great deal about ethical questions, and this might well suggest philosophers were right to think that ethical argument obeyed unique rules of reasoning. However, the emotivist doctrine struck at the very root of this notion in asserting that ethical language was intrinsically meaningless. Not denying that people engaged in disputes about ethics, the logical positivists were able to argue that the only thing of significance in such arguments fell squarely within the province of science. Ayer drew this conclusion quite clearly.

For we certainly do engage in disputes which are ordinarily regarded as disputes about questions of value. But, in all such cases, we find, if we consider the matter closely, that the dispute is not really about a question of value, but about a question of fact.

(Ayer 1946:110)

Generally, then, objective intellectual inquiry corresponds to scientific investigation, and science is identical with the nomological, verificationist natural science that employed the tools of deductive logic. The logical positivists thought that these were particularly important conclusions to draw, because they feared science was in danger of incorporating a host of irrational, spiritualist notions that might set back the human progress science had assisted over the last two centuries.

Robbins was very sympathetic to this concern. ${ }^{5}$ In his view economics had also suffered as a science on account of its failure to define its subject matter properly. He disparaged past attempts to describe economics as "the study of the causes of material welfare" (Robbins 1932, 1935: 9), and also insisted that as the study of resource allocation decisions economics only investigated ends-means relationships, not the ends of economic activity themselves.

[T] he subject matter of Economics is essentially a series of relationships 
- relationships between ends conceived as the possible objectives of conduct, on the one hand, and the technical and social environment on the other. Ends as such do not form part of this subject-matter. Nor does the technical and social environment. It is the relationships between these things and not the things in themselves which are important for the economist.

These relationships, Robbins went on to argue, existed in economics in a small number of essentially incontrovertible generalizations upon experience. In the simple theory of value and exchange where production is not at issue, the "main postulate" concerned individuals' capacity for arranging their preferences in order.

The propositions of economic theory, like all scientific theory, are obviously deductions from a series of postulates. And the chief of the postulates are all assumptions involving in some way simple and indisputable facts of experience related to the way in which the scarcity of goods which is the subject-matter of our science actually shows itself in the world of reality. The main postulate of the theory of value is the fact that individuals can arrange their preferences in an order, and in fact do so.

(pp. 78-9)

The "main postulate in the theory of production", Robbins continued, was the law of diminishing returns. There was then a law of dynamics. From these foundations, all "the complicated theorems of advanced analysis ultimately depend". And though "the more complicated applications of these propositions involves the use of a great multitude of subsidiary postulates ... [t] truth of the deductions from this structure depends, as always, on their logical consistency" (p. 79).

Clearly, then, though Robbins characterizes economics in the seemingly practical terms of means and ends, his view of its subject matter bears little relation to the traditional view of practical reasoning. Two things make this especially apparent. First, his insistence that the structure of economic argument employs postulates, theorems and logical consistency demonstrates that Robbins placed considerable weight on using traditional deductive reasoning in economics. Indeed, the desire to employ straightforward deductive argument in economics seems to have played an important role in Robbins's project of redefining economics, since his elimination of the material causes of welfare and the ends of economic activity from the domain of economics effectively serves to restrict its subject matter to sets of generalizable relationships that then readily function as propositions in deductive arguments. Second, though Robbins refers to ends-means relationships, his ends-means relationships explicitly exclude any consideration of the ends of action. Yet practical reasoning, as the investigation of purposive 
behavior and intentional action, examines both how individual actions are informed by intentions and how the intended ends of action are re-evaluated according to the success of our actions. The ends of action cannot thus be excluded from consideration of ends-means relationships if one is concerned to explain individuals' processes of practical reasoning, and Robbins's willingness to do this consequently betrays a commitment to a different approach to explaining economic behavior.

Why, then, did Robbins think that the ends of action fell outside the domain of economics? Here the influence of logical positivist thinking in the 1930s seems to have been crucial. Like the logical positivists, Robbins believed that the topic of the ends of action belonged to the domain of ethics, and that ethics and economics are "two fields of inquiry ... not on the same plane of discourse" because ethics concerned values and economics - as a science concerned facts (p. 148). This difference, he emphasized, gave the propositions of economics a special advantage over those in ethics. Because factual propositions are susceptible to empirical verification, true propositions can be thought objective. The propositions of ethics, in contrast, must be thought subjective, because they lack an evaluation procedure comparable with empirical verification. Indeed, this conclusion was central to Robbins's famous critique of interpersonal utility comparisons. Earlier (cardinal) utility theorists had thought it possible to compare changes in one individual's wellbeing with those of another's. Robbins insisted that this involved value judgments, because "There is no means of testing the magnitude of A's satisfaction as compared with B's" (pp. 139-40). Value judgments, however, were subjective, and this implied that interpersonal comparisons of utility should be excluded from economics.

Robbins thus followed the logical positivists both in demarcating science and non-science and in regarding ethics as non-science. Yet the objections of Robbins and the logical positivists to ethics applied no less to other forms of practical reasoning, so that on their understanding social science had to be a deductive nomological form of investigation that had as its object the explication of causal connections in the social world. It was for this reason that Robbins termed economics a natural science, and asserted that "the propositions of Economics are on all fours with the propositions of all other sciences" (p. 104). But, surely, this conclusion also must strike many as a curious one, since Robbins's Essay is most well known for its conclusion that "Economics is the science which studies human behaviour as a relationship between ends and scarce means which have alternative uses" (p. 16). How can a science of behavior in which individuals must make decisions over resource use be a natural science? The simple answer to this question is that it cannot. The more complicated answer is that while Robbins was correct to emphasize the choice as central to economics, he was mistaken in thinking that this did not require a conception of the methodology of economics distinct from the model offered by natural science. 


\section{SOCIAL SCIENCE AND PRACTICAL REASONING}

On the assumption that contemporary economics largely follows Robbins in employing natural science methods of thinking and analysis, just how, then, is practical reasoning in economic life misrepresented? When we consider a demand relationship, the quantity demanded of a good is termed a dependent variable and the good's price is termed an independent variable. Economists sometimes hasten to add that this does not imply that price and quantity demanded are causally connected, with changes in the former necessitating changes in the latter. Yet this assertion, it seems, is at odds with the practice of attempting empirically to verify demand (and other) relationships in economics. Presumably the goal of empirical work is to show that there exist true relationships between whatever variables are the subject of investigation. But if such relationships truly obtain, then it follows that changes in independent variables are responsible for bringing about changes in dependent variables, and this is the idea of causal connection. True relationships, that is, are causal relationships, and thus the goal of empirical work in economics is to uncover causal laws governing economic phenomena, despite the fact that this implies that economic behavior is deterministic.

Note that this conclusion is not undermined by saying that whatever demand behavior was in the past, it might be different in the future. If a demand relationship is said to have obtained in the past as a matter of fact, then it has already been asserted that price changes caused changes in quantity demanded. It is true that the world might well be different in the future, but if one later establishes a different set of empirically true relationships between variables, then one has only shown that different causal connections then obtained between those variables. Moreover, since we suppose that the laws of nature do not change, the establishment of a new causal relationship between variables seems to imply that the original specification of the model involved in the initial testing was somehow mistaken. Essentially, then, once one begins the project of finding true general relationships in economic behavior one commits oneself to the idea that causal relationships govern that behavior.

Thus, although most economists believe that empirically established relationships in economics are meant to explain choice or decision behavior, the idea that these relationships display causal connections means that there is not only no need to refer to such behavior in the description of these relationships, but moreover to do so betrays a misunderstanding of the nature of choice behavior itself. A true empirical relationship between two variables implies that these variables will always be associated in a particular manner. But if they are to be invariably associated in some particular manner, then it cannot be the case that an agent has chosen to respond in the way this relationship requires, because choice presupposes the ability to act otherwise than one has. That is, that such a relationship obtains implies that agents must 
always behave in accordance with it. At bottom, then, the idea of there being empirically established relationships in economics is incompatible with the idea of individuals exercising genuine choice or decision behavior in economic life, this despite the fact that economists generally believe themselves to be explaining choice behavior.

Economists who accordingly model economic behavior functionally to permit empirical investigation must implicitly employ a theoretical understanding of behavior that precludes the exercise of agent choice. ${ }^{6}$ One way that this occurs is through a violation of the central assumption underlying practical reasoning as a distinct form of reasoning, namely, that the conclusion to a practical argument does not compel action or, as it was put above, that the demonstrated desirability of something does not entail its being desired by any given individual. From this perspective, economists wedded to the natural science model of explanation rule out choice behavior by effectively requiring that desirability does imply desire. That is, should some item be shown to be desirable for an individual, that individual must also desire that item, or else (as the theoretical syllogism has it) be charged with acting inconsistently. In economics, of course, failure to act as the model requires is termed irrational behavior, and only "acting" as one's preferences and opportunity sets dictate is regarded as rational. True, economists do not deny that individuals sometimes fail to act as their models require, but they do deny that there is a logic or form of reasoning that might render this behavior rational. ${ }^{7}$ In this way they demonstrate their implicit commitment to a natural science interpretation of economic behavior.

How, then, should economic behavior be described so as to be said purposive and intentional? The difficulty with the standard model is that the so-called goal or end, utility maximization, is not really a goal in the sense of being an end determined by the agent. Rather, the agent maximizes utility, because he or she possesses an unchosen preference structure that, upon being confronted with a set of stimuli designated as that agent's opportunity set (prices, income etc.) which defines the relevant setting and circumstances, dictates a rational "choice". A reasonable characterization of behavior that is purposive and intentional, however, would involve agent determination of goals, followed by subsequent action in accordance with those goals, followed by the evaluation of the appropriateness of the actions selected to the task of achieving the chosen goals, finally followed by reconsideration of goals that may be chosen in the future. In essence, purposive behavior involves an interaction between actions and goals that involves a process or series of steps in reasoning. The domain of practical reasoning, as investigated by philosophers (e.g. Anscombe 1957; Gautier 1963; Edgely 1969; Norman 1971; Von Wright 1971; Korner 1974; Raz 1975, 1978), represents the field of logic that attempts to systematize the rules of inference involved in this form of reasoning. Without looking into this literature, it is possible to say briefly how the standard model of behavior used in economics circumvents 
the sort of analysis that would be involved in an account of the interaction of actions and goals.

In the standard model of economic behavior, preferences are both complete and stable (Stigler and Becker 1977). Thus, if we examine behavior over a period of time, we can assume that action does not modify intention and that the goal of action, namely, to maximize utility, is constant. On this view, desirability dictates desire or preferences dictate action (given an opportunity set), essentially because the agent has a single, unchanging behavior function. In contrast, were agents to engage in goal-determining behavior on account (at least in part) of the actions they undertook, then the analysis of their behavior as agents would need to assume that their objectives at any one point in time were incompletely determined, else they would be incapable of change. In effect, that our ends or goals may be reevaluated in light of actions performed tells us that our ends or goals at any one point in time do not fully represent us. This incomplete determination is both incompatible with a functional analysis of behavior and also necessary to any theory of practical reasoning based on an interaction of actions and goals. The standard theory of economic behavior, then, achieves its results - and excludes a genuine theory of choice - by exhaustive definition of the agent's goals in a welldefined objective function. Clearly, too, it is determinacy at this level which underlies the natural science approach in economics, since the project of discovering causal connections in any sphere depends upon treating behavioral relationships in functional terms.

A genuine choice theory of economic behavior, accordingly, needs to avoid functional analysis and preserve an element of indeterminacy in the goalsetting behavior of the economic agent. Practical inference as a logic of endsmeans interaction, it might also thus be said, turns on recognizing an important asymmetry between the effects of ends on means (how our actions are informed by our intentions) and the effects of means on ends (how we revise our goals in light of the results of our actions). While how our means address our ends is usually a relatively straightforward, technical matter, how our ends are revised in light of the results of our actions is by comparison quite obscure, if only because of the difficulty in seeing clear patterns in our changing goals. The implication of this is that goals and ends possess an element of ambiguity that we may be mistakenly inclined to minimize to achieve more concrete results in social science. This was something that Robbins and the logical positivists seem to have concluded in judging ends as valuational (which is correct) and as such irrational (which is disputable). ${ }^{8}$

There have been, it should be noted, many economists who have resisted this conception of the nature of economics, and some who have addressed the role Robbins's thinking has played in bringing it about. Among Austrian economists, Israel Kirzner (1960) has argued that Robbins's thinking about the nature of economics was particularly responsible for the confused view of economic decision-making held by so many contemporary economists. For 
Kirzner, this approach led economists to over-appreciate static equilibrium methods and under-appreciate the active role of the entrepreneur in the economy. From the English Marshallian tradition, J. M. Keynes attacked Robbins's view of economics, precisely because he thought it led to a mistaken characterization of economics as a natural science. Adopting an older English political economy designation of social science as moral science, Keynes argued that the intentional nature of human behavior necessitated an altogether different methodology for economics.

I also want to emphasise strongly the point about economics being a moral science. I mentioned before that it deals with introspection and with values. I might have added that it deals with motives, expectations, psychological uncertainties. One has to be constantly on guard against treating the material as constant and homogeneous.

(Keynes 1971-89: XIV, p. 300)

However, neither Kirzner nor Keynes have had much influence on economic methodology, whatever their influence on economic theory itself. Indeed, the tremendous explosion of econometric techniques and methods that has occurred in recent decades dates from about the time of Keynes's criticisms of Robbins, when individuals such as Jan Tinbergen first began to apply multiple correlation techniques to macroeconomic data (1939). ${ }^{9}$ Perhaps in the case of Keynes, whose influence on economic theory has been considerable, it may have been that, though he distanced himself from traditional deductive logic in his own early work on probability theory (Keynes 1971-89: VIII), he never systematically went on to work out his thoughts about practical logic. Thus, though his emphasis on "motives, expectations, and psychological uncertainties" was entirely appropriate to an investigation of purposive behavior and intentional action, his failure to provide a clear rationale for this emphasis left his message muted.

\section{IMPLICATIONS FOR EMPIRICAL AND QUANTITATIVE WORK IN ECONOMICS}

What are the implications of the analysis above for empirical economic methodology and for the use of quantitative methods in economics? The argument here has been that the behavior of agents in economic life must be understood as exhibiting practical reasoning, and that economics needs to avoid representing agent behavior in natural science terms, that is, as a behavior explainable in terms of generalizable relationships that imply causal laws. This argument does not imply, it should be emphasized, that economics does not aim at producing true propositions about economic behavior. As a social science, of course, economics aims no less at producing truth than does natural science. Thus, while strict causal laws of the sort that are sought in natural science have no place in economics on the argument here, facts are 
still very much an object of economic analysis. A classification of the kinds of factual propositions compatible with the assumption that individuals exercise practical reason in their economic behavior should accordingly provide guidelines for empirical economic research in economics. There seem to be two sorts of factual propositions in economics and social science.

First, there are those general factual propositions that might be said to describe non-causal, "structural" relationships in the economy. Even though intentional, economic behavior in many contexts seems lethargic in the sense that slowly changing circumstances are often associated with little variation in individuals' ends and actions. Moreover, many economic categories and concepts involve a level of aggregation that typically obscures the intentional component in individual economic behavior. Thus, relationships that are "structural", in the sense that they largely omit reference to individual choice behavior and describe patterns of events that are simply highly confirmed rather than explainable as the products of agent choice behavior, are reasonably given mathematical and statistical treatment. Note that this has implications for our interpretation of the error term involved in probabilistic analysis. If we assume that behavioral equations tested possess at most an implicit reference to agents' intentional behavior, then the error term in such equations should no longer be said to reflect random elements in underlying agent behavior (since the idea of the true model being deterministic is contrary to our view of choice). Rather the error term should be thought to reflect the degree to which our "structural" equations fail to approximate agents' underlying intentional behavior. That is, the error term seems better understood as a measure of our failure to capture the essential variability of choice behavior in our effort to produce reasonably well confirmed but not exact characterizations of aggregate activity.

Second, there are those particular factual propositions that aim only at explaining specific historical events. Since actions have causal impact, a large body of information may potentially be integrated and organized to produce a knowledge of past economic behavior and relationships. Economic history in this sense aims to explain unique historical occurrences as a result of the particular choices made by particular economic agents in particular circumstances. That is, economic history, by making the historical process its subject of investigation, focuses directly upon individuals' practical reasoning, or how intention informs action and is revised in light of its results. Put differently, this domain of economic investigation places its chief emphasis on documenting the development and change in agents' motivations for action, and thus it is the traditional historian's methodologies rather than statistician's techniques that are what are required for this portion of empirical economics.

These two kinds of factual propositions, however, appear to exhaust the allowable domain for empirical research in economics and social science. Only the former, however, allows for the use of contemporary quantitative 
and statistical methods, and even in this connection considerable caution must be exercised in interpreting econometric results. It would thus be going too far to say that mathematical representation of economic relationships is an altogether misconceived enterprise. Rather the proper conclusion seems to be that mathematics is often misused in economics due to a failure to recognize the limitations placed on explanation in social science. Too much of contemporary economics can indeed be characterized as natural science masquerading as social science. What, then, it seems fair to recommend is that economists devote less effort to functional representation of economic behavior and more effort to investigating the dynamic and variable character of economic choice. This no doubt would diminish the value of much contemporary equilibrium analysis - a mainstay of modern economics. But it presumably would lead to better economic analysis and, perhaps, better explanation and prediction of economic events.

\section{NOTES}

1 Among contemporary economic theorists with this view are the Austrians, who treat economic decision-making as a process of creative discovery, and traditional institutionalist economists, who emphasize the complex role an economy's institutional fabric plays in influencing choice.

2 Gordon's (1992) monumental study of the history and philosophy of social science continually emphasizes this fundamental divide between natural and social science.

3 See Gordon (1992: 590ff.) for an account of the rise and fall of logical positivism.

4 Neither Robbins nor the logical positivists, it turned out, were really consistent on this last, central point. In particular, their methodological strictures themselves clearly lacked empirical foundations.

5 To be sure, Robbins drew very much upon the Austrian school of economics for his principal inspiration, and this in important respects meant that his methodology was more apriorist than would have suited the logical positivists. The argument here concerns their common commitment to deductivist reasoning.

6 A good example here is Elster (1989). Elster insists that the proper method for the social sciences is one that investigates causal mechanisms. When he comes to the analysis of choice and explanation of action his expedient is to speak of "two successive filtering operations" in our constraints and opportunities (p. 13). Nowhere in his discussion is he able to persuasively demonstrate that this analysis of behavior permits us to explain the real phenomena of choice behavior.

7 Indeed, originally some of the most innovative work attempting to explain this apparently widespread "irrational" behavior as reasonable invoked the notion of a bounded or procedural rationality (Simon 1957). Such an analysis, however, still presupposes the natural science orientation in economics.

8 Robbins is sometimes taken to have purged the remaining classical political economy elements from the neoclassical revolution in economic theory of the later nineteenth century, where the essence of that revolution was to make choice behavior central to economic analysis. On the interpretation here, that revolution was more responsible for making a deterministic functional analysis based on the 
differential calculus the cornerstone of economics. Marshall's two blades of the supply-and-demand scissors, then, were the determinations of psychology and technology.

9 Keynes also, it is worth noting, advanced one of the first major critiques of econometrics.

\section{REFERENCES}

Anscombe, G. E. M. (1957) Intention, Oxford: Basil Blackwell.

Ayer, A. J. (1936, 1946) Language, Truth and Logic, New York: Dover Publications.

Davidson, D. (1980) Essays on Actions and Events,

Edgley, R. (1969) Reason in Theory and Practice, London: Hutchinson.

Elster, J. (1989) Nuts and Bolts, Cambridge: Cambridge University Press.

Gautier, D. (1963) Practical Reasoning, Oxford: Oxford University Press.

Gordon, S. (1992) The History and Philosophy of Social Science, London: Routledge.

Keynes, M. J. (1971-89) The Collected Writings, ed. D. Moggridge, London: Macmillan.

Kirzner, I. (1960) The Economic Point of View, Kansas City, KS: Sheed \& Ward.

Korner, S. (ed.) (1974) Practical Reason, Oxford: Blackwell.

Norman, R. (1971) Reasons for Action, Oxford: Blackwell.

Raz, J. (1975) Practical Reasons and Norms, London: Hutchison. (ed.) (1978) Practical Reason, Oxford: Oxford University Press.

Robbins, L. (1932, 1935) An Essay on the Nature and Significance of Economic Science, London: Macmillan.

Simon, H. (1957) Models of Man: Social and Rational, New York: Wiley.

Stevenson, C. L. (1937) "The emotive meaning of ethical terms", Mind.

Stigler, G. and Becker, G. (1977) "De gustibus non est disputandum", American Economic Review 67 (2): 76-90.

Tinbergen, J. (1939) A Method and Its Application to Economic Activity, Geneva: League of Nations.

Von Wright, G. H. (1971) Explanation and Understanding, Ithaca, NY: Cornell University Press. 